\title{
Geoparque Seridó, RN: Avaliação dos seus geossítios com base nas categorias de valor intrínseco, científico, turístico e de uso/gestão
}

\author{
Geopark Seridó, RN: Evaluation of its geosites based on the categories \\ intrinsic, scientific, tourism and use/management value
}

\begin{abstract}
Geoparque Seridó, RN: Evaluación de sus geositios con base en las categorías de valor intrínseco, científico, turístico y de uso/gestión
\end{abstract}

\section{Cristiane Soares Cardoso Dantas Gomes}

Doutoranda em Turismo na Universidade Federal do Rio Grande do Norte

Mestre em Turismo (PPGTUR/UFRN)

crisscdantas@gmail.com / Orcid: https://orcid.org/0000-0002-2135-8584

Marcos Antonio Leite do Nascimento

Docente no Programa de Pós-Graduação em Turismo

Doutor em Geodinâmica pela UFRN

marcos@geologia.ufrn.br / Orcid: https://orcid.org/0000-0002-8158-7186

Carlos Alberto Freire Medeiros

Docente no Programa de Pós-Graduação em Turismo

Doutor em Administração pela USP

carlosalbertofreiremedeiros@gmail.com / Orcid: https://orcid.org/0000-0002-3830-1162

Data de submissão:30/03/2017 - Data de aceite:16/07/2018

\begin{abstract}
Resumo: O projeto Geoparque Seridó é resultado de um estudo técnico e diagnóstico que embasou a inventariação de 25 geossítios, sendo reformulado e atualmente abrangendo 16 geossítios, contemplado em seis municípios no estado do Rio Grande do Norte (Cerro Corá, Lagoa Nova, Currais Novos, Acari, Carnaúba dos Dantas e Parelhas). Esses locais apresentam um patrimônio geológico único utilizado para diferentes finalidades. Dessa forma, a pesquisa tem o intuito de evidenciar os valores que podem ser encontrados nesses locais. Para confirmar tais valores, foi utilizada uma metodologia de quantificação do patrimônio geológico. A pesquisa evidenciou dois geossítios (Mina Brejuí e Pico do Totoró) de relevância internacional e oito geossítios de relevância nacional (Serra Verde, Vale Vulcânico, Cânions dos apertados, Açude Gargalheiras, Cruzeiro de Acari, Xiquexique, Açude Boqueirão e Mirador), além de mostrar quais geossítios têm finalidade científica, turística. Os resultados oriundos da pesquisa evidenciaram que a área tem sim viabilidade para a efetivação da proposta do Geoparque e ratificam a importância do lugar ao ser embasado nos valores apontados pela pesquisa.
\end{abstract}


Palavras chave: Geoturismo, Geoparques, Geoparque Seridó, Estado do RN.

Abstract: The Seridó Geopark Project was the result of a technical and diagnostic study based on an inventory of 25 geosites. It was redesigned, and currently encompasses 16 geosites located in six municipalities in the state of Rio Grande do Norte (Cerro Corá, Lagoa Nova, Currais Novos, Acari, Carnaúba dos Dantas and Parelhas). These sites present a unique geological heritage used for different purposes. This research aims to highlight the values that can be found in these places. To confirm these values, a quantitative and quantitative geological heritage quantification methodology was used. Thus, the research highlights two geosites of international importance (Mina Brejuí and Pico do Totoró) and eight geosites of national importance (Serra Verde, Vale Vulcânico, Cânion dos Apertados, Açude Gargalheiras, Cruzeiro de Acari, Xiquexique, Açude Boqueirão and Mirador). It also shows which geosites have scientific and tourist purpose. The research results demonstrate that the area has feasibility for the implementation of the Geopark proposal, and ratify the importance of the place, based on the values pointed out by the research.

Keywords: Geotourism, Geopark, Seridó Geopark, State of RN.

Resumen: El proyecto Geoparque Seridó es el resultado de un estudio técnico y diagnóstico que se basó en el inventario de 25 geositios, siendo reformulado y actualmente abarcando 16 geositios, ubicado en seis municipios en el estado de Rio Grande do Norte (Cerro Corá, Lagoa Nova, Currais Novos, Acari, Carnaúba dos Dantas y Parelhas). Estos lugares presentan un patrimonio geológico único utilizado para diferentes finalidades. De esta forma, la investigación tiene el objetivo de mostrar los valores que pueden ser encontrados en estos lugares. Para confirmar dichos valores, fue utilizada una metodología de cuantificación del patrimonio geológico. La investigación constato dos geositios (Mina Brejuí y Pico do Totoró) de relevancia internacional y ocho geositios de relevancia nacional (Serra Verde, Vale Vulcânico, Cânions dos apertados, Açude Gargalheiras, Cruzeiro de Acari, Xiquexique, Açude Boqueirão y Mirador), además de mostrar cuales geositios tienen finalidad científica, turística. Los resultados oriundos de la investigación mostraron que el área si tiene viabilidad para la realización de la propuesta de Geoparque y corroboran la importancia del lugar al ser embasado en los valores apuntados por la investigación.

Palavras clave: Geoturismo, Geoparques, Geoparque Seridó, Estado de RN.

\section{Introdução}

Os geoparques surgem da união de quatro territórios (Alemanha, França, Espanha e Grécia) que, por meio do programa Leader + , se uniram por estar passando pelos mesmos problemas como grande êxodo rural e dificuldades financeiras. Assim, esses territórios se unificaram para experimentar o conceito de geoparque. A iniciativa deu tão certo, que antes o que eram quatro territórios, hoje é um novo programa da UNESCO (Global Geoparks), a exemplo do Programa do Homem e da Bioesfera (Man and Biospheres - MAB Programme) e do Patrimônio da Humanidade (World Heritage), oficializado em Novembro de 2015, em que sítios do patrimônio geológico representam parte de um conceito holístico de proteção, educação e desenvolvimento sustentável que deve gerar atividade econômica por meio do turismo, compreendendo sítios geológicos (ou geossítios, locais que apresentam um patrimônio geológico de singular valor) de importância científica, raridade ou beleza. Atualmente, o Programa Mundial de Geoparques da UNESCO conta com 140 geoparques em 38 países (dados de maio de 2017).

No âmbito do Brasil, há o projeto Geoparques do Brasil, que busca identificar locais potenciais para a implantação de geoparques e dentre as 32 propostas existentes, encontra-se a do Geoparque Seridó. O projeto Geoparque Seridó é resultado de um estudo técnico que passou por algumas modificações e contempla atualmente 16 geossítios em seis municípios (Cerro Corá, Lagoa Nova, Currais Novos, Acari, Carnaúba dos Dantas e Parelhas). Alguns locais já apresentam visitações seja para fins científicos, educativos ou turísticos, bem como algumas iniciativas ligadas à conservação.

Dessa forma, o objetivo desse estudo foi avaliar que tipo de valores está presente nos geossítios inseridos no território do Geoparque Seridó. Para isso, utilizou-se a metodologia de quantificação do patrimônio geológico, desenvolvida por Pereira (2010), que contempla quatro dimensões 
de valores: intrínseco, científico, turístico e de uso/gestão. Além do mais, os resultados oriundos desses valores permitiram identificar que tipo de relevância apresenta cada geossítio, seja do ponto de vista internacional, nacional, regional ou local.

Esses resultados subsidiam estratégias de planejamentos para esses locais, uma vez que se torna possível desenvolver ações com foco específico para cada geossítio, permitindo o desenvolvimento do geoturismo nesses espaços, reverberando em um turismo mais holístico e integrado com as premissas de educação e desenvolvimento.

Assim, o estudo versa sobre temas como Geodiversidade, Geoconservação e Geoturismo: Trinômio importante para a solidez de um Geoparque; Geoparques: Ferramentas de geoconservação e promoção do geoturismo; Geoparque Seridó: Uma possível realidade no Estado do Rio Grande do Norte, seguidos da metodologia, dos resultados e das conclusões que serão abordados a seguir.

\section{Geodiversidade, Geoconservação e Geoturismo: Trinômio importante para a solidez de um Geoparque.}

O estudo exaustivo da biodiversidade aguçou a atenção de alguns pesquisadores para uma parte da natureza que tem interferência no desenvolvimento de espécies, habitat e ecossistemas. E esta parte não foi levada em consideração por certo tempo e que agora vem sendo trabalhada e discutida de modo a equilibrar o seu conhecimento com a biodiversidade. Essa parte nada mais é que a Geodiversidade.

A utilização do termo Geodiversidade é recente. Conforme Gray (2005), ele "começou a ser utilizado por geólogos e geomorfológicos na década de 90 para descrever a variedade do meio abiótico". O termo foi introduzido no sentido de estabelecer uma analogia com o termo biodiversidade, além de integrar em seu conceito todos os elementos abióticos de um território.

Com os esclarecimentos sobre o tema, percebeu-se a importância da Geodiversidade. Ela é resultado da interação entre paisagem, fauna, flora e cultura. A geologia e a geomorfologia determinam a distribuição dos habitats, das espécies e a forma como o ser humano organiza seu espaço geográfico (Araújo, 2005).
Por ser uma fração importante da natureza, a Geodiversidade necessita ser conservada. Para tanto, estratégias de conservação são relevantes. Mediante isso, surge a geoconservação, que são ações voltadas para a conservação dos elementos da geodiversidade por meio da educação geocientífica, além de ser mecanismos que visam ao uso sustentável nesses locais e de seus recursos.

Nessa nova abordagem, a geoconservação reconhece que os componentes não vivos do ambiente natural são tão importantes quanto os elementos vivos, necessitando de uma gestão adequada e que, ao mesmo tempo, integre essas duas porções da natureza. Além do mais, a geoconservação tem um papel significativo a desempenhar para ajudar a garantir o desenvolvimento sustentável por meio de conservação e promoção científica, educacional, recreativa, cultural e importantes características de locais e espécimes (Burek \& Potter 2008).

Dentre as iniciativas de geoconservação, encontra-se o geoturismo, uma atividade que possibilita aos turistas uma visão mais científica do que contemplativa da paisagem. Ela possibilita a promoção da geoconservação e esta, por sua vez, é uma ferramenta indispensável na conservação da geodiversidade mundial, seja representada por geossítios ou pelo patrimônio geológico (Bento \& Rodrigues 2010).

Conforme Dowling (2010), o geoturismo está emergindo como um novo fenômeno global. É uma atividade do turismo onde enfatiza as feições geológicas e as tem como seu principal atrativo. Esta atividade permite um novo olhar à visitação turística, não tornando esta meramente contemplativa, mas vindo a permitir o entendimento dos locais visitados, resultando na compreensão e na importância daqueles aspectos geológicos, promovendo sua conservação.

Azevedo (2007), em sua tese de doutorado, intitulada Patrimônio Geológico e Geoconservação no Quadrilátero Ferrífero, Minas Gerais: Potencial para a Criação de um Geoparque da UNESCO, traz a seguinte definição sobre geoturismo:

[...] um segmento da atividade turística que tem o patrimônio geológico como seu principal atrativo e busca sua proteção por meio da conservação de seus recursos e da sensibilização do turista, utilizando, para isto, a interpretação deste patrimônio 
tornando-o acessível ao público leigo, além de promover a sua divulgação e o desenvolvimento das Ciências da Terra (Azevedo, 2007, p. 23).

É válido ressaltar que o geoturismo possui uma grande força no desenvolvimento de uma região. Mas para que seu desenvolvimento ocorra de maneira eficaz, é interessante que as partes interessadas da região tenham um comprometimento com o processo de desenvolvimento, além do mais, é importante que ocorra a incorporação das preocupações locais no processo de planejamento.

O geoturismo é uma atividade recomendada para ocorrer em áreas que valorizam atrações turísticas locais com ênfase nos aspectos geológicos. A iniciativa, que vem ganhando destaque neste sentido, são os geoparques, que são ferramentas importantes no desenvolvimento, visto que valorizam atrações turísticas locais com ênfase nos aspectos geológicos.

\section{Geoparques: Ferramentas de Geoconservação e Promoção do Geoturismo}

Os geoparques nada mais são que espaços com limites bem definidos e que possuem uma área que serve de apoio ao desenvolvimento socioeconômico local que enfatiza como atrações turísticas os aspectos geológicos. Nele deve conter geossítios que são locais de especial importância por possuir valores de cunho científico, turístico, educativo, histórico e cultural.

O seu surgimento foi fruto de uma reflexão no $30^{\circ}$ congresso internacional de geologia ocorrido em Pequim em 1996, que tinha como base a dificuldade de gerir de forma simultânea a proteção e a promoção do patrimônio geológico por meio do desenvolvimento econômico sustentável dos territórios onde está esse patrimônio (Zouros 2004). Foi então que quatro territórios (França, Alemanha, Grécia e Espanha), por meio de um programa europeu chamado Leader + , puderam desenvolver o conceito de geoparque em cooperação com a UNESCO.

Em 2000 esses quatro territórios, sob os auspícios da UNESCO, formaram a Rede Europeia de Geoparques. Essa rede tem unificado os territórios de toda a Europa, que compartilha esses objetivos e que estão agora trabalhando juntos de uma forma ativa e dinâmica para atingilos. Atualmente, a Rede Europeia conta com 73 geoparques.

O sucesso da Rede Europeia de Geoparques levou a UNESCO a se envolver um pouco mais nessa nova dinâmica, sendo criado em 2004 a Rede Global de Geoparques. O objetivo da Rede Global é fornecer uma plataforma de cooperação e intercâmbio entre especialistas e profissionais em matéria de patrimônio geológico sob auspícios da UNESCO. A rede se estende por todas as regiões do mundo e reúne grupos que compartilham valores comuns, interesses ou fundos (Eder \& Patzak, 2004).

A ideia de um Geoparque global está sendo adotada por um número crescente de países pelo fato de estarem se tornando populares em razão da sua combinação de conservação, desenvolvimento sustentável e envolvimento da comunidade. Hoje, a rede conta com 140 geoparques distribuídos em 38 países.

O desenvolvimento econômico que um geoparque pode trazer a uma localidade pode ser por meio de pequenas e médias empresas que desenvolvem produtos e serviços, como a fabricação de uma lembrança associada a algum elemento do Geoparque, atividades relacionadas com lazer, como: ciclismo; escalada; atividades culturais, artísticas; dentre outras, além de ser mudança social, estimulando o Geoturismo nessas áreas. Além disso, um geoparque atinge seus objetivos por meio da educação, da conservação e do turismo.

Para que o geoparque atinja sua eficiência e eficácia em termos de melhoria para os envolvidos, é importante o engajamento de todos que possam colaborar com seu planejamento, desenvolvimento, inovação, divulgação e promoção. Por isso a importância de atividades inovadoras, a realização de consultorias com empresários locais com a finalidade de explicar a importância econômica e social que os geoparques podem gerar, bem como estimular parcerias com artistas locais, operadoras de turismo, setores privados, meios de hospedagem, restaurantes, além do envolvimento dos moradores para que possam contribuir com a conservação do local e promoverem atividades educacionais, gerando os benefícios que realmente se espera com um geoparque.

O Brasil é um país detentor de um grande potencial para criação de geoparques, em função da rica geodiversidade que apresenta com 
testemunhos geológicos importantes, aliado a aspectos ecológicos, arqueológicos, culturais. Em razão disto, a CPRM - Serviço Geológico do Brasil lançou em 2006 o projeto Geoparques Brasil. Esse projeto tem como premissa básica "a identificação, levantamento, descrição, diagnóstico e ampla divulgação de áreas com potencial para futuros geoparques no território nacional, bem como o inventário e quantificação de geossítios" (Schobbenhaus \& Silva 2012, P.19).
As propostas de áreas com potencial de se transformarem em Geoparques são descritas na Figura 1.

Dentre as iniciativas de criação de novos Geoparques no território brasileiro, encontra-se a proposta do Geoparque Seridó, sendo mais bem detalhado no tópico seguinte.

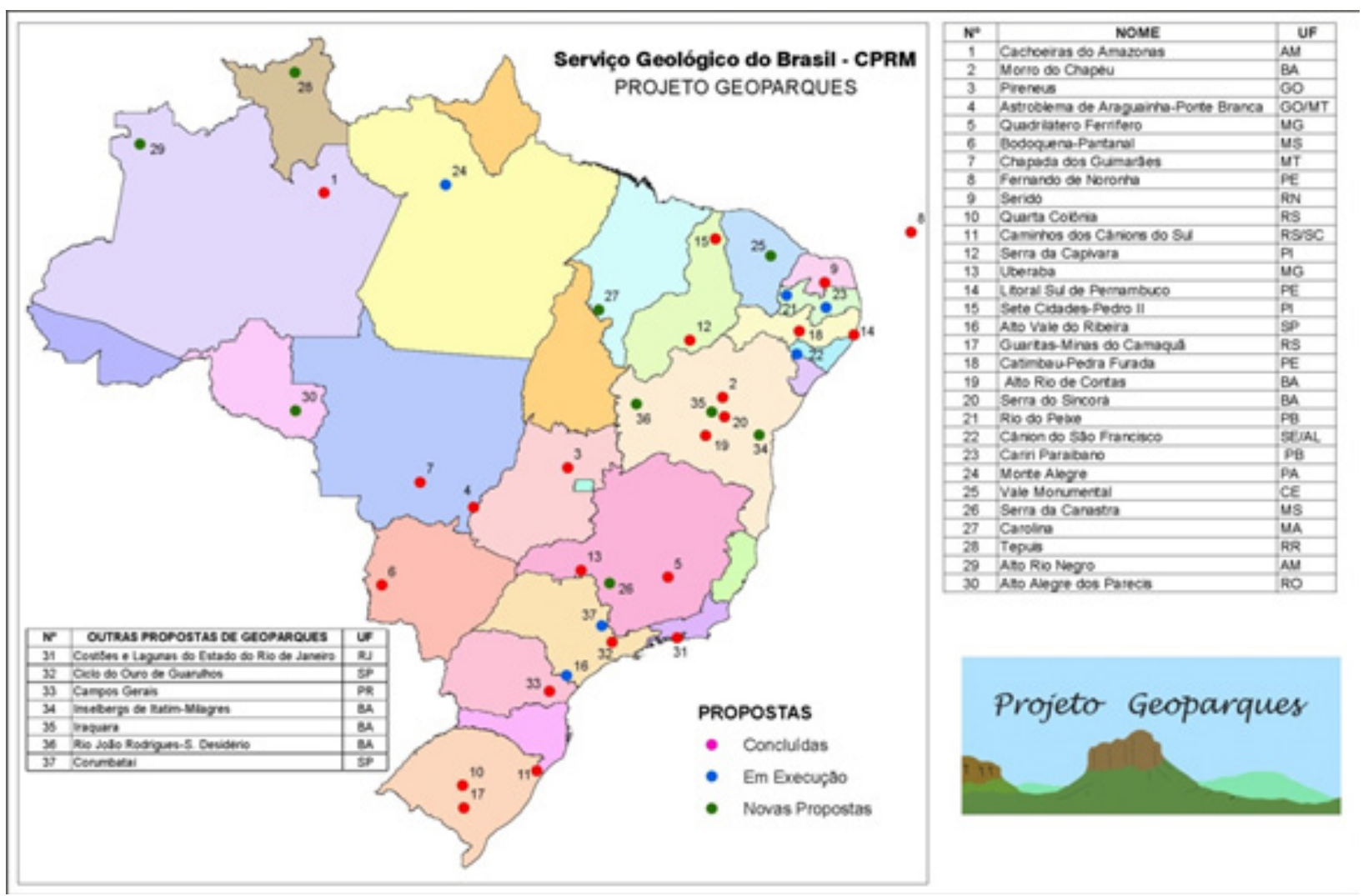

Fonte: http://cprm.gov.br/publique/Gestao-Territorial/Geoparques-134.

\section{Geoparque Seridó: Uma possível realidade no Estado do Rio Grande do Norte}

O Geoparque Seridó está localizado na porção centro-sul do Estado do Rio Grande do Norte e decorre de um estudo técnico e diagnóstico que embasou inicialmente a inventariação de vinte e cinco geossítios. Entretanto, houve uma modificação no projeto no que se refere à sua delimitação territorial (Medeiros et al. 2017). Por essa razão, a área que contempla o Geoparque Seridó foi reduzida, abrangendo atualmente dezesseis geossítios (Figura 2) nos seguintes municípios: Cerro Corá (geossítios Serra Verde, Cruzeiro de Cerro Cora e Vale Vulcânico); Lagoa
Nova (Mirante de Santa Rita); Currais Novos (Pico do Totoró, Morro do Cruzeiro, Mina Brejuí, Cânion dos Apertados); Acari (Gargalheiras, Poço de Arroz, Cruzeiro de Acari e Marmita do Rio Carnaúba); Carnaúba dos Dantas (Xiquexique e Monte do Galo); Parelhas (Açude Boqueirão e Mirador). 
Figura 2: Localização da área proposta para o Geoparque Seridó.

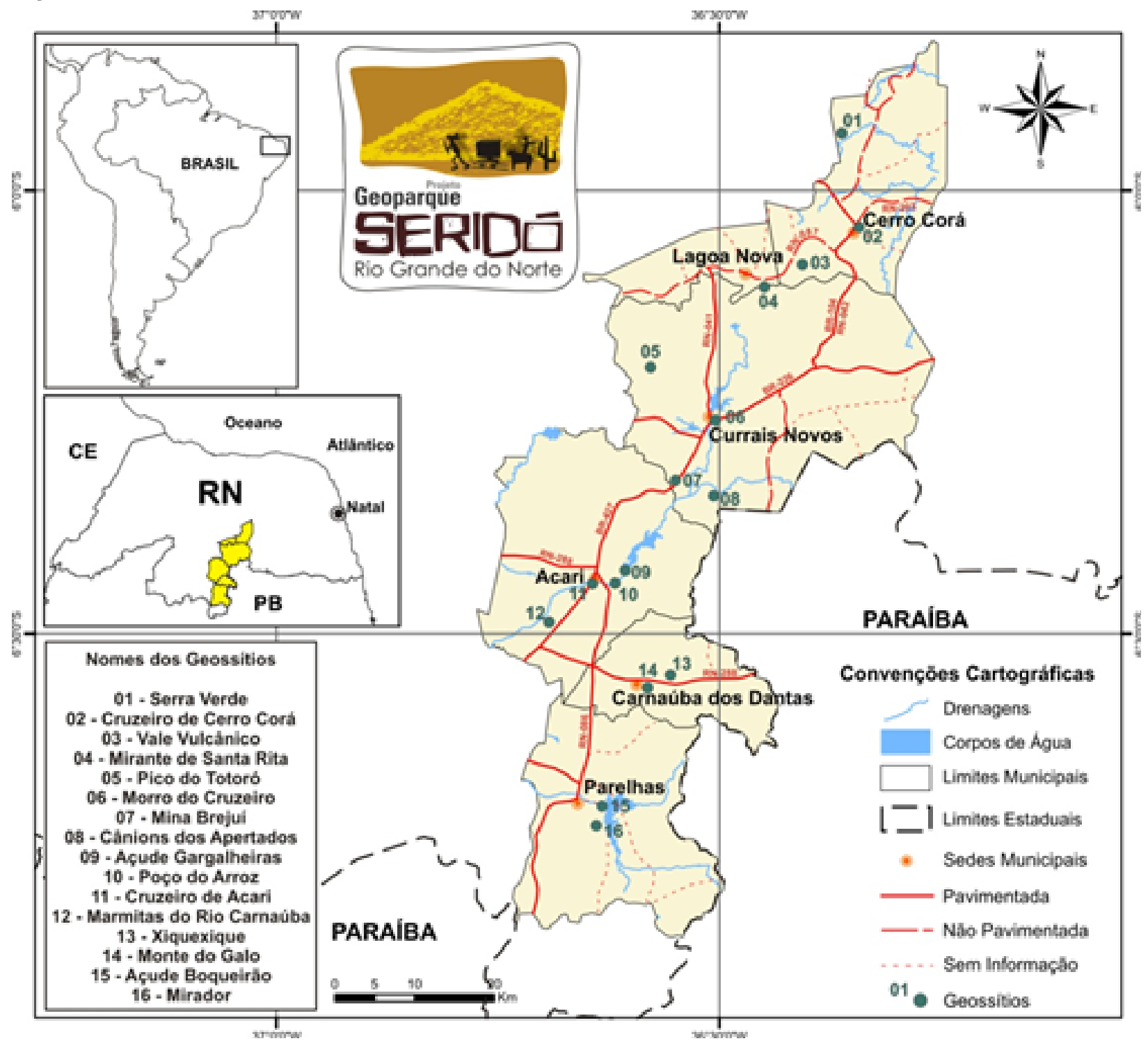

Fonte: Medeiros et al. (2017).

A área que abrange a proposta do Geoparque Seridó contempla iniciativas ligadas ao estímulo à atividade turística, como o Polo Turístico do Seridó, criado pelo Governo do Estado do Rio Grande do Norte, que é um espaço socioeconômico homogêneo com vantagens competitivas e vocacionais, com o objetivo de integrar a cadeia produtiva do turismo, além do Roteiro Seridó, cuja finalidade é apoiar o desenvolvimento turístico da região, assegurando a sustentabilidade, com iniciativas no âmbito do turismo, educação ambiental, tecnologia de alimentos, gestão de cooperativas e outras associações, artesanato, empreendedorismo, promoção e marketing, capacitação técnica e gerencial, tendo como públicos-alvo empresários, gestores municipais, professores, estudantes e produtores rurais, entre outros (Nascimento e Ferreira 2010).

Destaque na região é o papel desempenhado pelo IPHAN/RN na preservação do patrimônio arqueológico da região, seja por meio do cumprimento da legislação relacionada à arqueologia preventiva ou por meio de iniciativas de socialização que garantem uma visitação mais controlada aos sítios.

Como a região que contempla o geoparque apresenta características peculiares e mostra potencial para o desenvolvimento de atividades, utilizou-se uma metodologia de quantificação para aferir os valores turísticos e de uso e gestão dos geossítios correspondeste à proposta do geoparque, metodologia esta oriunda de Pereira (2010). 


\section{Metodologia}

Para realizar a quantificação dos dezesseis geossítios do Geoparque Seridó, utilizou-se a metodologia de quantificação do patrimônio geológico elaborada por Pereira (2010). É dividida em quatro categorias de valor: valor intrínseco, científico, turístico e de uso e gestão. Desta forma, para cada categoria de valor foi obtida uma nota por meio de uma média aritmética dos valores atribuídos ao conjunto de parâmetros, como pode ser visto a seguir:

Valor intrínseco (vi): Avaliaram-se a raridade, a integridade, a vulnerabilidade associada aos processos naturais e a variedade de elementos da geodiversidade que o local apresenta. A obtenção do valor dessa categoria é por meio do seguinte cálculo:

$$
(\mathrm{A} 1+\mathrm{A} 2+\mathrm{A} 3+\mathrm{A} 4) / 4
$$

Valor Científico (Vci): Refere-se aos trabalhos de pesquisa realizados no local, às suas potencialidades para ilustrar processos ou aspectos relevantes da geologia da área, sua relevância didática e variedade de elementos relacionados com outras temáticas. Para tanto, tem-se o seguinte cálculo:

$$
(\mathrm{B} 1+\mathrm{B} 2+\mathrm{B} 3+\mathrm{B} 4) / 4
$$

Valor Turístico (Vtur): Esta categoria permite avaliar a realidade atual quanto à utilização turística do geossítio. Abrange as características ligadas à acessibilidade, à presença de infraestrutura, à utilização do local no momento presente e à eventual presença de medidas de controle de visitantes, permitindo uma avaliação futura da capacidade de carga do geossítio. $O$ cálculo é obtido por meio da seguinte fórmula:

$$
(\mathrm{C} 1+\mathrm{C} 2+\mathrm{C} 3+\mathrm{C} 4+\mathrm{C} 5) / 5
$$

Valor de Uso/Gestão (Vug): Tratase de todos os parâmetros relacionados à relevância cultural (lendas, religião), condição socioeconômica das áreas do entorno, nível oficial de proteção, possibilidade de utilização dos geossítios e vulnerabilidade perante o uso. Esses critérios indicam impactos sociais e viabilidade de utilização futura do geossítio. Os resultados são obtidos pela seguinte fórmula:

$$
(\mathrm{D} 1+\mathrm{D} 2+\mathrm{D} 3+\mathrm{D} 4+\mathrm{D} 5+\mathrm{D} 6+\mathrm{D} 7) / 7
$$

Obtidas as notas de cada categoria de valor, foram calculadas as pontuações para o Valor de Uso Científico (VUC), o Valor de Uso Turístico (VUT) e o Ranking de Relevância. Este último parâmetro estabelece o nível de relevância ou influência (local, regional, nacional ou internacional) para os geossítios. Calculou-se também o Valor de Conservação (VC), que é o indicativo da relevância do geossítios em termos de conservação (PEREIRA 2010). Conforme a metodologia, para calcular os valores dos usos dos locais, o autor adotou as seguintes ponderações e equações:

Valor de Uso Científico (VUC): Calculado a partir da média ponderada dos valores intrínsecos (vi) e científicos (Vci), em que foi atribuído um peso maior para o Vci, visto que este indicador é obtido por parâmetros que expressam a disponibilidade de trabalhos científicos já realizados no local, a representatividade para ilustrar processos geológicos e seu potencial didático e sua diversidade de interesses dentro das geociências ou demais temáticas relacionadas com outras áreas de estudo. Logo o VUC indica a relevância científica do geossítio. Já o Vi expressa a potencial existência de elementos de interesse científico no local, visto que demonstra sua abundância/raridade, nível de conservação e possibilidade de visualização dos aspectos de interesse, vulnerabilidade aos processos naturais e variedade de elementos da geodiversidade associados. Mediante a isto, o cálculo do VUC é obtido da seguinte forma:

$$
\mathrm{VUC}=(2 \mathrm{xVi}+3 \mathrm{xVci}) / 5
$$

Valor de Uso Turístico (VUT): Expressa o potencial de utilização do geossítio como atrativo turístico calculado a partir da média ponderada dos valores turísticos (Vtur) e de uso/gestão (Vug). Neste cálculo, foi atribuído um peso maior ao Vtur, pois nesta categoria são avaliados o aspecto estético, a acessibilidade, a presença de infraestrutura e as condições atuais de uso do lugar. Todavia o Vug representa o potencial de utilização futura do geossítio mediante sua valorização e divulgação. Foi estabelecida a seguinte equação:

$$
\mathrm{VUT}=(3 \mathrm{xVtur}+2 \mathrm{xVug}) / 5
$$

Valor de Conservação (VC): Revela a importância do geossítio para fins de conservação dos elementos da geodiversidade, obtendo-se por 
meio da média ponderada dos valores intrínsecos (Vi), científico (Vci) e de uso/gestão (Vug), atribuindo um peso maior ao Vi. Segundo Pereira (2010), foram utilizados o Vci e o Vug pelo fato de a conservação do patrimônio natural ser encarada como uma atividade de impacto positivo e que, além disto, considere a importância científica do local, por isto estes indicadores foram utilizados. Para o cálculo do VC, utilizou-se a seguinte equação:

$$
\mathrm{VC}=(3 \mathrm{xVi}+\mathrm{Vci}+\mathrm{Vug}) / 5
$$

Ranking de Relevância (R): Obtida a partir dos índices de valor de uso científico (VUC) e do Valor de Uso Turístico (VUT). Para a obtenção do cálculo, os valores foram divididos por 20 , o que representa o número total de parâmetros adotados nesta metodologia, sendo multiplicados por 100 com a intenção de normatizar os resultados. Ao final, realizou-se uma média ponderada em que foi atribuído um peso maior ao VUC, obtendo o seguinte cálculo:

$$
\mathrm{R}=\{2 \mathrm{x}[(\mathrm{VUC} / 20) \mathrm{x} 100]+[(\mathrm{VUT} / 20) \mathrm{x} 100]\} / 3
$$

Os resultados obtidos permitem uma seriação dos geossítios para cada tipo de uso pretendido, seja científico, turístico e de conservação, bem como a definição de sua relevância em uma escala local, regional, nacional e internacional, onde:

Geossítios de relevância local: locais onde $\mathrm{R}=<10$.

Geossítios de relevância regional: locais onde $10<\mathrm{R}<$ valor médio obtido para a relevância dos conjuntos de geossítios avaliados.

Geossítio de relevância nacional: locais onde $\mathrm{R}>$ valor médio obtido para a relevância dos conjuntos de geossítios avaliados.

Geossítios de relevância internacional: locais onde $\mathrm{R}>$ valor médio obtido para a relevância do conjunto de geossítios avaliados e onde, simultaneamente, os parâmetros A2 e A3 são maiores ou iguais a três e os parâmetros B1, $\mathrm{B} 2, \mathrm{C} 2$ e C3 maiores ou iguais a dois.

\section{Resultados e Discussões}

Diante da quantificação dos geossítios (Figura 3), no que se refere à categoria de valor intrínseco, o $1^{\circ}$ lugar ficou com o geossítio Mina Brejuí (pontuação 4), o $2^{\circ}$ com os geossítios
Pico do Totoró e Serra Verde $(3,75)$. O $3^{\circ}$ lugar com os geossítios Vale Vulcânico, Cânions dos Apertados, Açude Gargalheiras, Monte do Galo e Açude Boqueirão $(3,25)$. O $4^{\circ}$ lugar com os geossítios Cruzeiro de Cerro Corá, Mirante Santa Rita, Morro do Cruzeiro, Marmita do Rio Carnaúba, Xiquexique (3), enquanto que o $5^{\circ}$ lugar ficou com os geossítios Cruzeiro de Acari, Poço de Arroz e Mirador (2,75). O valor médio obtido para esta categoria foi de 3,05 e, com base neste resultado, oito geossítios ficaram acima da média (Mina Brejuí, Pico do Totoró, Serra Verde, Vale Vulcânico, Cânions dos Apertados, Açude Gargalheiras, Monte do Galo e Açude Boqueirão).

Em relação à categoria de Valor Científico dos geossítios do Geoparque Seridó, em $1^{\circ}$ lugar ficou o Geossítio Pico do Totoró $(3,75)$, o $2^{\circ}$ com o Geossítio Mina Brejuí (3,25), enquanto que em $3^{\circ}$ lugar tem-se Serra Verde, Vale Vulcânico, Xiquexique e Açude Boqueirão $(3,0)$. O $4^{\circ}$ ficou com os geossítios Cânions dos Apertados e Açude Gargalheiras (2,75), o $5^{\circ}$ lugar com Cruzeiro de Acari e Mirador $(2,5)$, o $6^{\circ}$ lugar com Marmitas do Rio Carnaúba $(2,0)$, o $7^{\circ}$ lugar com Morro do Cruzeiro $(1,25)$. Em $8^{\circ}$ lugar tem-se os geossítios Poço do Arroz e Cruzeiro de Cerro Corá $(0,75)$, em $9^{\circ}$ lugar Mirante Santa Rita $(0,5)$ e em $10^{\circ}$ o geossítio Monte do Galo $(0,25)$. Para esta categoria de valor, a média obtida foi 1,93. Os geossítios que obtiveram valor acima da média foram: Pico do Totoró, Mina Brejuí, Serra Verde, Vale Vulcânico, Xiquexique, Açude Boqueirão, Cânions dos Apertados, Açude Gargalheiras, Cruzeiro de Acari, Mirador e Marmitas do Rio Carnaúba. Estes que ficaram acima da média apresentam diferentes tipos de rochas ígneas e metamórficas, além de geoformas diferenciadas, bem como presença de fósseis e registros rupestres que representam testemunhos geológicos e arqueológicos, por essas razões já recebem visitas por sua importância científica. 
Figura 3: Resultados obtidos para os valores (a) intrínseco, (b) científico, (c) turístico e (d) de uso e gestão
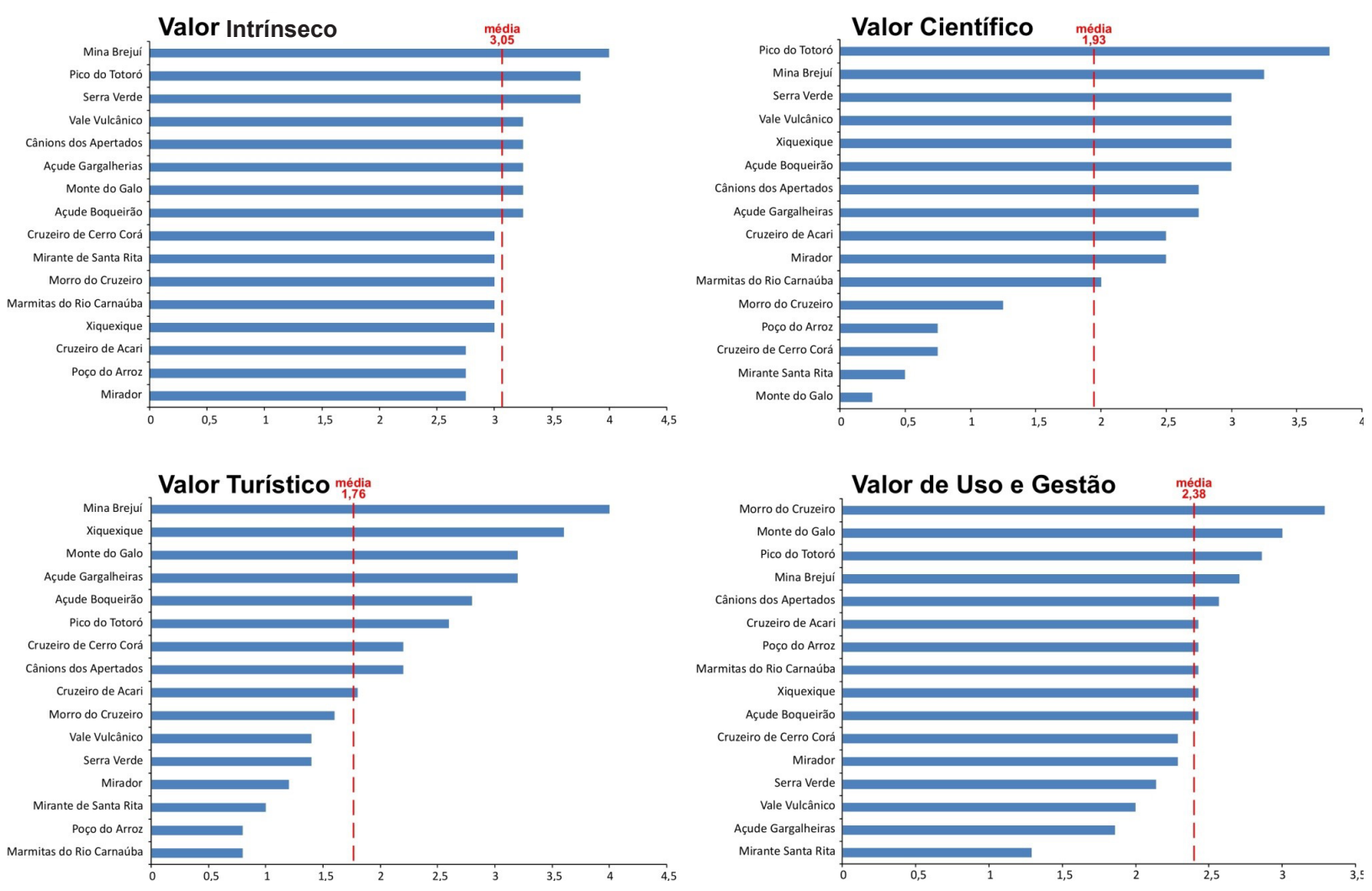

Em relação à categoria de valor turístico, a maior pontuação ficou com a Mina Brejuí (pontuação de 4,00), o $2^{\circ}$ lugar ficou com o geossítio Xiquexique $(3,60)$, o $3^{\circ}$ com Monte do Galo e o Açude Gargalheiras (3,20), o $4^{\circ}$ lugar com Açude Boqueirão $(2,80)$, o $5^{\circ} \mathrm{com}$ Pico do Totoró $(2,60)$ e o $6^{\circ}$ com Cruzeiro de Cerro Corá e Cânions dos Apertados $(2,20)$. Em $7^{\circ}$ lugar ficou o Cruzeiro de Acari $(1,80)$, em $8^{\circ}$ lugar o Morro do cruzeiro $(1,60)$, o $9^{\circ}$ lugar ficou com os geossítios Vale Vulcânico e Serra Verde $(1,40)$, o $10^{\circ}$ com o geossítio Mirador $(1,20)$. O $11^{\circ}$ lugar ficou com o Mirante de Santa Rita $(1,00)$, enquanto que os geossítios Poço de Arroz e Marmita do Rio Carnaúba $(0,80)$ ficaram em $12^{\circ}$ lugar. O valor médio obtido para esta categoria de valor foi 1,76. Com base nesse valor, os geossítios que obtiveram valores acima da média foram Mina Brejuí, Xiquexique, Monte do Galo, Açude Gargalheiras, Açude Boqueirão, Pico do Totoró, Cruzeiro de Cerro Corá, Cânions dos Apertados e Cruzeiro de Acari. O motivo pelo qual esses geossítios apresentam um valor acima da média é que estes já recebem visitações, além de alguns apresentarem uma boa infraestrutura seja dentro do geossítio ou no seu entorno, o que permite um diferencial, até mesmo quando avaliado conforme a metodologia.

Alguns deles apresentam, seja de forma legalizada ou não, algum tipo de controle de visitantes, o que conta como ponto a favor dos geossítios em critério de avaliação da metodologia utilizada. Atrelado a isso, a presença de infraestrutura, acessibilidade, utilização em curso são critérios que foram avaliados na pesquisa. Então, quanto melhor esses aspectos ao geossítio, maior será sua pontuação.

A categoria de Valor Uso/Gestão permite um indicativo dos impactos sociais e da viabilidade de utilização futura dos geossítios (PEREIRA, 2010). Na $1^{\circ}$ colocação ficou o geossítio Morro do Cruzeiro $(3,29)$, em $2^{\circ}$ lugar Monte do Galo $(3,00)$, o $3^{\circ}$ lugar Pico do Totoró $(2,86)$, o $4^{\circ}$ lugar com a Mina Brejuí (2,71), o $5^{\circ}$ lugar com os geossítio Cânion dos Apertados, $(2,57)$, o $6^{\circ}$ Cruzeiro de Acari, Poço de Arroz, Marmita do Rio Carnaúba, Xiquexique e Açude Boqueirão $(2,43)$. O $7^{\circ}$ Cruzeiro de Cerro Corá e Mirador (2,29), o $8^{\circ}$ Serra Verde $(2,14)$, o $9^{\circ}$ Vale Vulcânico $(2,00)$, o $10^{\circ}$ Açude Gargalheiras $(1,86)$ e o $11^{\circ}$ com o geossítio Mirante Santa Rita $(1,29)$. Para esta categoria de valor, a média obtida foi 2,38, por essa razão, os geossítios que ficaram acima deste valor foram Morro do Cruzeiro, Monte do Galo, Pico 
do Totoró, Mina Brejuí, Cânion dos Apertados, Cruzeiro Acari, Poço de Arroz e Marmita do Rio Carnaúba, Xiquexique e Boqueirão.

Como esta categoria também demonstra a viabilidade de utilização futura dos geossítios, os que ficaram acima da média, alguns deles possuem um apelo histórico, religioso, científico e caso fossem feitos investimentos, poderia se tornar de um atrativo com apelo turístico maior. Alguns geossítios apresentam inscrições rupestres e eles poderiam ser mais explorados sustentavelmente, já que em alguns não são tão explorados a favor do turismo e da comunidade.

Outro dado obtido foram os resultados para o Valor de Uso Científico (Figura 4) dos geossítios da proposta do Geoparque Seridó, cuja finalidade expressa o potencial científico consagrado ou inexplorado dos geossítios, como afirma Pereira (2010).

Em relação a esse valor de uso, em primeiro lugar o geossítio Pico do Totoró $(3,75)$, o segundo lugar com o geossítio Mina Brejuí $(3,55)$, o terceiro com o geossítio Serra Verde $(3,30)$, o quarto os geossítios Vale Vulcânico e Açude Boqueirão $(3,10)$. O quinto lugar com o geossítio Xiquexique (3), o sexto com os geossítios Cânion dos Apertados e Açude Gargalheiras (2,95). Na sétima colocação encontram-se o geossítios
Cruzeiro de Acari e Mirador (2,60), o oitavo com os geossítios Marmita do Rio Carnaúba $(2,40)$, o nono com o geossítio Morro do Cruzeiro $(1,95)$. O décimo lugar com o geossítio Cruzeiro de Acari $(1,65)$, o décimo primeiro com o geossítio Poço de Arroz, o décimo segundo lugar com o geossítio Mirante de Santa Rita, décimo terceiro com os geossítios Monte do Galo (1,45).

Em relação ao Valor de Uso Turístico (Figura 4), categoria esta que expressa o potencial de utilização do geossítio como atrativo turístico, obtiveram-se os seguintes resultados: o primeiro lugar ficou com a Mina Brejuí $(3,49)$, o segundo com o geossítio Xiquexique $(3,13)$, o terceiro com o geossítio Monte do Galo $(3,12)$, o quarto lugar com o Pico do Totoró (2,70), o quinto com o geossítio Açude Gargalheiras $(2,66)$. O sexto lugar com o geossítio Açude Boqueirão $(2,65)$, o sétimo Cânion dos Apertados $(2,35)$, o oitavo lugar com o geossítio Morro do Cruzeiro (pontuação de 2,27). No nono lugar encontra-se o geossítio Cruzeiro de Cerro Corá $(2,23)$, o $10^{\circ}$ com o geossítio Cruzeiro de Acari $(2,05)$, o $11^{\circ}$ com o Serra Verde $(1,70)$, o $12^{\circ}$ lugar com o Vale Vulcânico (1,64), o décimo terceiro lugar com o geossítio Mirador (pontuação de 1,63). O 14 ${ }^{\circ}$ lugar com os geossítios Poço de Arroz e Marmita do Rio Carnaúba $(1,45)$, e o $15^{\circ}$ com o geossítio Mirante de Santa Rita $(1,11)$.

Figura 4: Resultados obtidos para os valores (a) uso científico, (b) uso turístico, (c) de conservação e (d) do raking de relevância
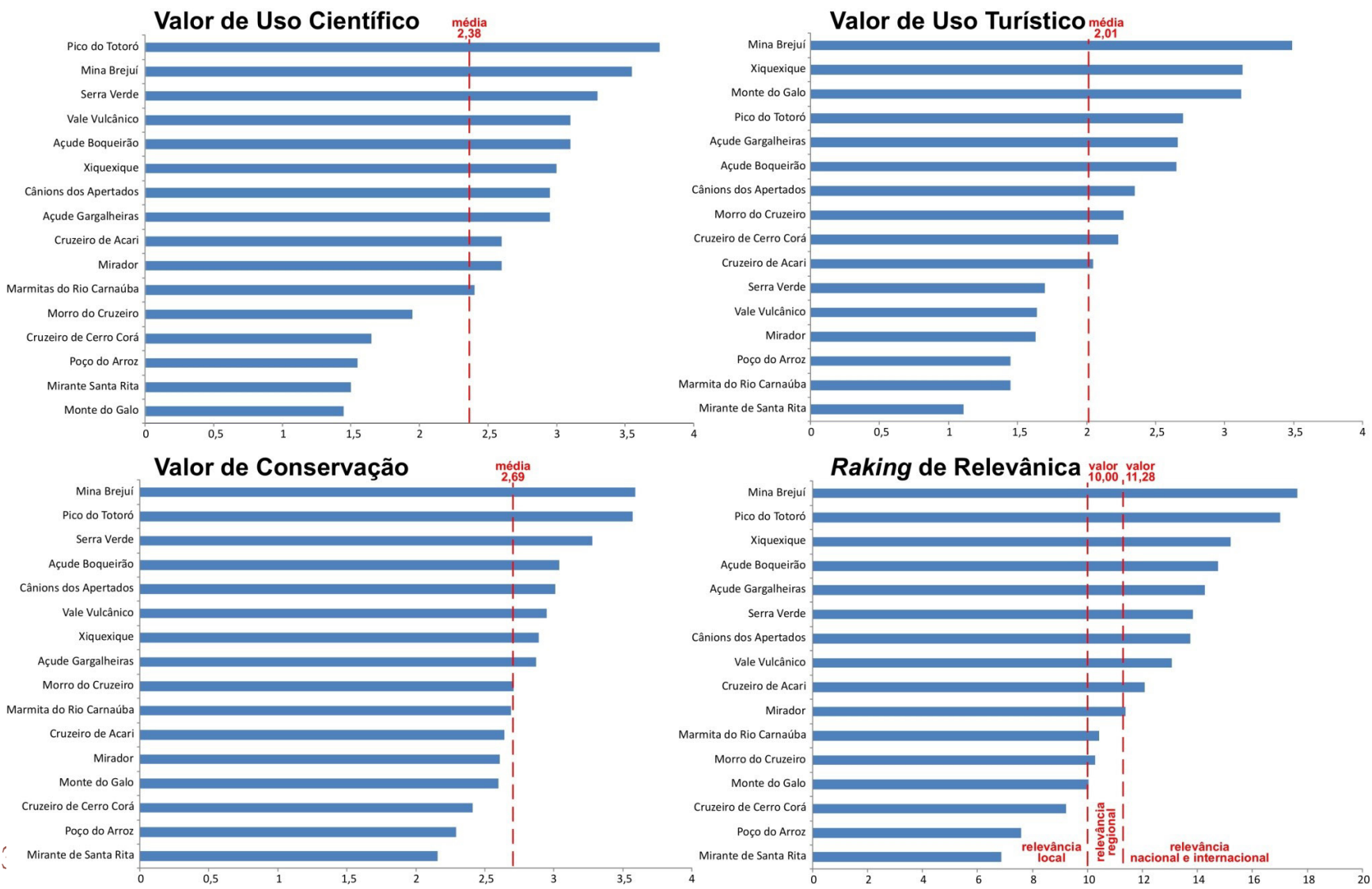
Após a categoria de Valor de Uso Turístico, seguiu-se com a análise do Valor de Conservação (Figura 4), o que permite expressar, conforme Pereira (2010), a importância do geossítio em termos de conservação dos elementos da geodiversidade, obtido por meio da média ponderada entre os valores intrínsecos (Vi), científico (Vci) e de Uso//gestão (Vug).

Desta forma, o $1^{\circ}$ lugar ficou com o geossítio Mina Brejuí $(3,59)$, o $2^{\circ}$ lugar com o Pico do Totoró $(3,57)$, o $3^{\circ}$ lugar com o Serra verde $(3,28)$, o $4^{\circ}$ com o Açude Boqueirão $(3,04)$, o $5^{\circ}$ com o Cânion dos Apertados $(3,01)$, a $6^{\circ}$ colocação com o Vale Vulcânico $(2,95)$, o $7^{\circ}$ lugar com o Xiquexique $(2,89)$, o $8^{\circ} \mathrm{com}$ o Açude Gargalheiras (2,87), $9^{\circ}$ lugar os geossítio Morro do Cruzeiro (2,71), o $10^{\circ}$ com o Marmita do Rio Carnaúba $(2,69)$. O $11^{\circ}$ lugar com o Cruzeiro de Acari $(2,64)$, o $12^{\circ}$ com o Mirador $(2,61)$, o $13^{\circ}$ lugar com o Monte do Galo $(2,60)$, o $14^{\circ}$ com o Cruzeiro de Cerro Corá $(2,41)$, o $15^{\circ}$ com o Geossítio Poço de Arroz (2,29). E finalmente, em 16º o Geossítio Mirante de Santa Rita $(2,16)$.

Com os dados, foi calculado o Ranking de Relevância (Figura 4) dos geossítios da proposta do Geoparque Seridó, resultante dos índices de Uso Científico (VUC) e do Valor de Uso Turístico (VUT). Como mencionado antes, o VUC e o VUT foram divididos por 20. Esse número representa o total de parâmetros adotado na metodologia, sendo posteriormente multiplicado por 100. O resultado obtido foram dos geossítios Mina Brejuí $(17,64)$ e Pico do Totoró $(17,00)$ como de relevância internacional. Os geossítios Xiquexique $(15,22)$, Açude Boqueirão $(14,75)$, Açude Gargalheiras $(14,27)$, Serra Verde $(13,83)$, Cânions dos Apertados (13,75), Vale Vulcânico $(13,07)$, Cruzeiro de Acari $(12,09)$ e Mirador $(11,39)$ de relevância nacional. Já os geossítios Marmitas do Rio Carnaúba $(10,42)$, Morro do Cruzeiro $(10,29)$ e Monte do Galo $(10,03)$ apresentam relevância regional e, por fim, os geossítios Cruzeiro de Cerro Corá $(9,22)$, Poço do Arroz $(7,59)$ e Mirante de Santa Rita $(6,86)$ são de relevância local.

Dessa forma, para sintetizar o conjunto das informações, no apêndice 1 , serão apresentados os resultados obtidos para os dezesseis geossítios que fazem parte do território do geoparque para as quatro categorias de valores (intrínseco, científico, turístico e de uso e gestão) e o apêndice 2 apresenta os resultados dos respectivos usos dos geossítios.

\section{Considerações Finais}

As iniciativas no âmbito do Geoparque Seridó no que se refere ao desenvolvimento do turismo já ocorrem de forma pontuada em alguns geossítios, uma vez que nem todos apresentam uma estrutura adequada, seja para receber os turistas ou até mesmo para promover a conservação da singularidade geológica desses espaços.

As estratégias de geoconservação, medidas utilizadas na conservação dos elementos da geodiversidade que apresentam características diferenciadas, convergem com a metodologia de quantificação utilizada na pesquisa, pois os resultados obtidos possibilitam um maior direcionamento e desenho das possíveis ações que podem ser conduzidas para cada geossítio especificadamente.

Desta forma, a metodologia de quantificação pontua os geossítios conforme quatro dimensões de valores: intrínseco, científico, turístico e de uso e gestão. Após a aplicação do instrumento, os resultados mostram dois geossítios (Mina Brejuí e Pico do Totoró) com relevância internacional e nove geossítios com relevância nacional (Serra Verde, Vale Vulcânico, Cânion dos Apertados, Açude Gargalheiras, Cruzeiro de Acari, Xiquexique, Açude Boqueirão e Mirador). Isso demonstra a expressividade dos geossítios para uso turístico e a possibilidade de uma perspectiva holística no território, uma vez que o geoparque combina na sua essência o turismo, a educação e o desenvolvimento sustentável.

Os resultados oriundos do valor de conservação só ratificam a importância de promover meios e ferramentas para conservar esses locais, uma vez que há a convergência de alguns resultados do valor do uso turístico e o valor de conservação, reforçando a questão holística presente no próprio conceito de geoparque.

Além do mais, agrega-se a potencialidade do local às atividades econômicas já desenvolvidas nesse território, favorecendo a inserção da comunidade, promovendo benefícios, além do interesse do Estado em diversificar sua oferta turística, visualizando no Geoparque Seridó uma alternativa para dinamizar o turismo no Rio Grande do Norte. Tais resultados mostram diferentes vieses de uso dos geossítios, desenvolvendo nesse território uma nova perspectiva de turismo com o foco na compreensão da paisagem. 


\section{Referências}

Araújo, E.L.S. (2005). Geoturismo: conceitualização, implementação e exemplo de aplicação no Vale do Rio Douro no setor Porto Pinhão. (Dissertação de mestrado). Retirado de http://www.progeo.pt/docs/ araujo_2005_r.pdf

Azevedo, Ú.R. (2007). Patrimônio Geológico e Geoconservação no Quadrilátero Ferrífero, Minas Gerais: Potencial para a Criação de um Geoparque da UNESCO. (Tese de Doutorado). Retirado de http://www.degeo.ufop.br/terraCiencias/ coloquios/IIcoloquio/doc_base/Patrimonio_ Geologico e Geoconservacao no QuadrilateroFerrifero,_Minas_Gerais:_Potencial_para_criacao_ de_um_Geoparque_da_Unnesco.pdf

Bento, L.C.M. \& Rodrigues, S.C. (2010). O geoturismo como instrumento em prol da divulgação valorização e conservação do patrimônio natural abiótico - uma reflexão teórica. Turismo e Paisagens Cársticas, 3(2),p, 57- 68.

Burek, C.V., \& Prosser, C.D. (2008). The History of Geoconservation. London, England: Geological Society Special Publication.

Dowling, R.K. (2010). Geotourism's Global Growth. Geoheritage 3:1-13.

Eder, F.W. \& Patzak, M.(2004). Geoparks-geological attractions: A tool for public education, recreation and sustainable economic development. Episodes, 27 (3) 162-164.

Gray, M. (2005). Geodiversity and Geoconservation: What, Why, and How? The George Wright Forum. 22(3), 4-9.

Medeiros, J.L., Nascimento, M.A.L., Perinotto, A.R.C. (2017). Práticas turísticas por meio da análise da dimensão ambiental em geossítios do Projeto Geoparque Seridó (RN). Revista Brasileira de Ecoturismo, São Paulo, V.10, n.3, ago/out, pp. $552-578$.

Nascimento, M.A.L. \& Ferreira, R.V.(2010). Projeto Geoparques - GEOPARQUE SERIDO - RN Proposta. Retirado de http://rigeo.cprm.gov. br/xmlui/bitstream/handle/doc/17155/serido. pdf?sequence $=1$

Pereira, R.G.F.A. (2010) Geoconservação e desenvolvimento sustentável na Chapada Diamantina, Bahia - Brasil. (Tese de Doutorado). Retirado de http://geoturismobrasil.com/artigos/ TESE-Ricardo\%20Fraga.pdf

Schobbenhaus, C. \& Silva, C.R. (2010). O papel indutor do Serviço geológico do brasil na criação de geoparques, apresentado no I Fórum do Patrimônio Cultural, Ouro Preto, 2010. Brasil: CPRMServiço Geológico do Brasil.

Zouros, N. (2004). The European Geopark network: Geological heritage protection and Local Development. Episodes 27(3), 165-171.
Contribuição de cada autor na elaboração do artigo

\section{Cristiane Soares Cardoso Dantas Gomes:} Levantamento bibliográfico, Introdução, desenvolvimento teórico do texto, coleta de dados, resultados, discussões e considerações finais.

Marcos Antônio Leite do Nascimento: Levantamento bibliográfico, metodologia, revisão.

Carlos Alberto Freire Medeiros: Revisão, análise dos resultados. 
Apêndice 1: Resultado da quantificação das quatro categorias de valores.

\begin{tabular}{|c|c|c|c|c|c|c|c|c|c|c|c|c|c|c|c|c|c|c|}
\hline & & 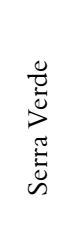 & 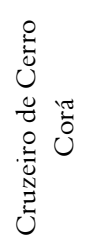 & 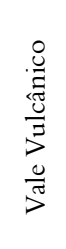 & 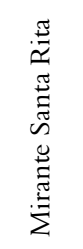 & $\begin{array}{l}0 \\
0 \\
0 \\
0 \\
+ \\
8 \\
0 \\
0 \\
.0 \\
0\end{array}$ & 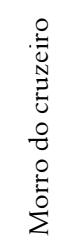 & $\begin{array}{l}\stackrel{\Xi}{0} \\
\stackrel{\Xi}{0} \\
\stackrel{\Xi}{\Xi}\end{array}$ & 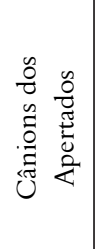 & 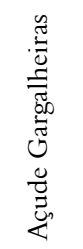 & 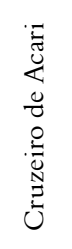 & \begin{tabular}{l}
$N$ \\
0 \\
\multirow{2}{*}{} \\
0 \\
0 \\
0 \\
0 \\
0
\end{tabular} & 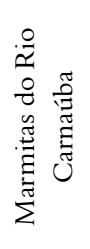 & $\begin{array}{l}\frac{0}{\pi} \\
0 \\
0 \\
\frac{0}{0} \\
\stackrel{\Xi}{0} \\
\sum^{0}\end{array}$ & 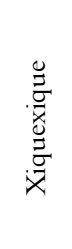 & 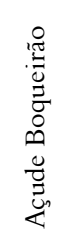 & 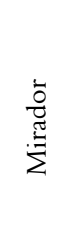 & \\
\hline & $\begin{array}{c}\text { A) Valor } \\
\text { Intrínseco (Vi) }\end{array}$ & & & & & & & & & & & & & & & & & \\
\hline A1 & $\begin{array}{c}\text { Vulnerabilidade } \\
\text { associada a processos } \\
\text { naturais }\end{array}$ & 4 & 4 & 2 & 4 & 4 & 4 & 4 & 4 & 4 & 4 & 4 & 4 & 4 & 4 & 4 & 4 & \\
\hline A2 & $\begin{array}{l}\text { Abundância/ } \\
\text { Raridade }\end{array}$ & 3 & 3 & 4 & 2 & 4 & 3 & 4 & 4 & 2 & 2 & 2 & 2 & 3 & 2 & 2 & 2 & $\begin{array}{c}\text { Média } \\
\text { do }\end{array}$ \\
\hline A3 & Integridade & 4 & 3 & 4 & 4 & 3 & 3 & 4 & 3 & 4 & 3 & 4 & 4 & 4 & 4 & 4 & 3 & Valor \\
\hline A4 & $\begin{array}{c}\text { Variedade de } \\
\text { elementos da } \\
\text { Geodiversidade }\end{array}$ & 4 & 2 & 3 & 2 & 4 & 2 & 4 & 2 & 3 & 2 & 1 & 2 & 2 & 2 & 3 & 2 & $\begin{array}{c}\text { Intrín- } \\
\text { seco }\end{array}$ \\
\hline \multicolumn{2}{|r|}{$\begin{array}{c}\text { Valor Intrínseco = } \\
(\mathrm{A} 1+\mathrm{A} 2+\mathrm{A} 3+\mathrm{A} 4) / 4\end{array}$} & 3,75 & 3 & 3,25 & 3 & 3,75 & 3 & 4 & 3,25 & 3,25 & 2,75 & 2,75 & 3 & 3,25 & 3 & 3,25 & 2,75 & 3,05 \\
\hline & $\begin{array}{c}\text { B) Valor Científico } \\
\text { (Vci) }\end{array}$ & & & & & & & & & & & & & & & & & \\
\hline B1 & $\begin{array}{c}\text { Objeto de } \\
\text { referências } \\
\text { bibliográficas (grau } \\
\text { de conhecimento } \\
\text { científico) }\end{array}$ & 3 & 1 & 3 & 0 & 4 & 0 & 4 & 3 & 4 & 3 & 0 & 3 & 0 & 4 & 3 & 3 & \\
\hline B2 & $\begin{array}{c}\text { Representatividade } \\
\text { de materiais e } \\
\text { processos geológicos }\end{array}$ & 2 & 0 & 4 & 0 & 4 & 2 & 4 & 4 & 2 & 4 & 0 & 2 & 0 & 2 & 4 & 2 & $\begin{array}{c}\text { Média } \\
\text { do }\end{array}$ \\
\hline B3 & $\begin{array}{c}\text { Diversidades de } \\
\text { interesse/temáticas } \\
\text { associadas }\end{array}$ & 3 & 0 & 1 & 0 & 3 & 1 & 1 & 0 & 1 & 1 & 1 & 1 & 1 & 2 & 1 & 1 & Valor \\
\hline B4 & Relevância Didática & 4 & 2 & 4 & 2 & 4 & 2 & 4 & 4 & 4 & 2 & 2 & 2 & 0 & 4 & 4 & 4 & $\begin{array}{l}\text { Cientí- } \\
\text { fico }\end{array}$ \\
\hline \multicolumn{2}{|r|}{$\begin{array}{l}\text { Valor Científico }= \\
(\mathrm{B} 1+\mathrm{B} 2+\mathrm{B} 3+\mathrm{B} 4) / 4\end{array}$} & 3 & 0,75 & 3 & 0,5 & 3,75 & 1,25 & 3,25 & 2,75 & 2,75 & 2,5 & 0,75 & 2 & 0,25 & 3 & 3 & 2,5 & 1,93 \\
\hline & $\begin{array}{l}\text { C) Valor Turístico } \\
\text { (Vtur) }\end{array}$ & & & & & & & & & & & & & & & & & \\
\hline C1 & Aspecto estético & 4 & 2 & 4 & 2 & 4 & 2 & 4 & 4 & 4 & 2 & 2 & 2 & 4 & 4 & 4 & 2 & \\
\hline $\mathrm{C} 2$ & Acessibilidade & 0 & 4 & 0 & 3 & 2 & 3 & 4 & 2 & 4 & 4 & 2 & 2 & 4 & 2 & 4 & 3 & \\
\hline C3 & $\begin{array}{c}\text { Presença de infra- } \\
\text { estrutura }\end{array}$ & 0 & 2 & 0 & 0 & 2 & 2 & 4 & 0 & 4 & 2 & 0 & 0 & 4 & 4 & 4 & 0 & $\begin{array}{c}\begin{array}{c}\text { Média } \\
\text { do }\end{array} \\
\end{array}$ \\
\hline $\mathrm{C} 4$ & $\begin{array}{c}\text { Existência de } \\
\text { utilização em Curso }\end{array}$ & 1 & 1 & 1 & 0 & 3 & 1 & 4 & 3 & 4 & 1 & 0 & 0 & 4 & 4 & 2 & 1 & Valor \\
\hline C5 & \begin{tabular}{|c|} 
Presença de \\
mecanismo de \\
controle de visitantes
\end{tabular} & 2 & 2 & 2 & 0 & 2 & 0 & 4 & 2 & 0 & 0 & 0 & 0 & 0 & 4 & 0 & 0 & $\begin{array}{c}\text { Turís- } \\
\text { tico }\end{array}$ \\
\hline \multicolumn{2}{|c|}{$\begin{array}{c}\text { Valor turístico }= \\
(\mathrm{C} 1+\mathrm{C} 2+\mathrm{C} 3+\mathrm{C} 4+\mathrm{C} 5) / 5\end{array}$} & 1,40 & 2,20 & 1,40 & 1,00 & 2,60 & 1,60 & 4,00 & 2,20 & 3,20 & 1,80 & 0,80 & 0,80 & 3,20 & 3,60 & 2,80 & 1,20 & 1,76 \\
\hline & $\begin{array}{l}\text { D) Valor de Uso/ } \\
\text { Gestão (Vug) }\end{array}$ & 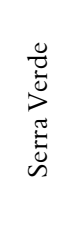 & 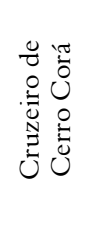 & $\begin{array}{l}\stackrel{8}{0} \\
\frac{\pi}{0} \\
\frac{3}{3} \\
\frac{0}{n} \\
>\end{array}$ & 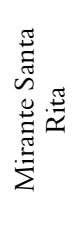 & $\begin{array}{l}0 \\
\stackrel{0}{0} \\
0 \\
\stackrel{0}{0} \\
0 \\
0 \\
.0 \\
0\end{array}$ & 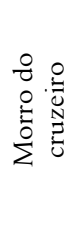 & 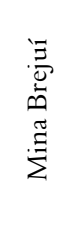 & 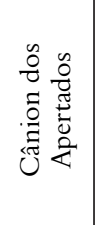 & 芠 & 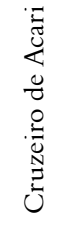 & $\begin{array}{l}N \\
0 \\
0 \\
0 \\
0 \\
0 \\
0 \\
0\end{array}$ & 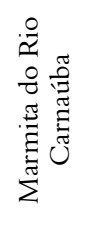 & 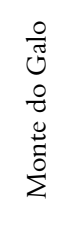 & $\begin{array}{l}\stackrel{0}{Z} \\
\stackrel{\vec{x}}{0} \\
\stackrel{\Xi}{\vec{x}}\end{array}$ & 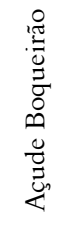 & 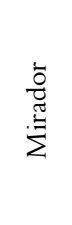 & \\
\hline D1 & Relevância cultural & 2 & 3 & 1 & 0 & 3 & 3 & 1 & 1 & 1 & 2 & 2 & 2 & 3 & 3 & 1 & 2 & \\
\hline D2 & $\begin{array}{l}\text { Relevância } \\
\text { econômica }\end{array}$ & 4 & 4 & 4 & 4 & 1 & 4 & 0 & 4 & 1 & 4 & 4 & 4 & 4 & 4 & 1 & 1 & \\
\hline D3 & $\begin{array}{c}\text { Nível oficial de } \\
\text { proteção }\end{array}$ & 0 & 0 & 0 & 0 & 0 & 0 & 0 & 0 & 0 & 0 & 0 & 0 & 0 & 0 & 0 & 0 & \\
\hline D4 & $\begin{array}{c}\text { Passível de utilização } \\
\text { econômica }\end{array}$ & 4 & 4 & 4 & 0 & 4 & 4 & 4 & 2 & 4 & 4 & 4 & 4 & 4 & 2 & 4 & 4 & \\
\hline
\end{tabular}




\begin{tabular}{|c|c|c|c|c|c|c|c|c|c|c|c|c|c|c|c|c|c|c|}
\hline D5 & $\begin{array}{l}\text { Vulnerabilidade } \\
\text { associada ao uso } \\
\text { antrópico }\end{array}$ & 2 & 2 & 2 & 2 & 2 & 2 & 4 & 2 & 2 & 2 & 2 & 2 & 4 & 2 & 4 & 2 & $\begin{array}{c}\text { Média } \\
\text { do }\end{array}$ \\
\hline D6 & $\begin{array}{c}\text { População do } \\
\text { núcleo urbano mais } \\
\text { próximo }\end{array}$ & 2 & 2 & 2 & 2 & 5 & 5 & 5 & 4 & 2 & 2 & 2 & 2 & 1 & 1 & 4 & 4 & $\begin{array}{c}\text { Valor } \\
\text { de }\end{array}$ \\
\hline D7 & $\begin{array}{l}\text { Condições sócio- } \\
\text { econômicas dos } \\
\text { núcleos urbanos } \\
\text { mais próximos }\end{array}$ & 1 & 1 & 1 & 1 & 5 & 5 & 5 & 5 & 3 & 3 & 3 & 3 & 5 & 5 & 3 & 3 & $\begin{array}{c}\text { Uso_- } \\
\text { Gestão }\end{array}$ \\
\hline $\begin{array}{r}\mathrm{Val} \\
(\mathrm{I}\end{array}$ & $\begin{array}{l}\text { or de Uso/Gestão }= \\
\mathrm{D} 1+\mathrm{D} 2+\mathrm{D} 3+\mathrm{D} 4+ \\
\mathrm{D} 5+\mathrm{D} 6+\mathrm{D} 7) / 7\end{array}$ & 2,14 & 2,29 & 2,00 & 1,29 & 2,86 & 3,29 & 2,71 & 2,57 & 1,86 & 2,43 & 2,43 & 2,43 & 3,00 & 2,43 & 2,43 & 2,29 & 2,38 \\
\hline
\end{tabular}

Fonte: Pesquisa de campo (2013).

Apêndice 2: Resultado da quantificação das categorias de uso e relevância.

\begin{tabular}{|c|c|c|c|c|c|c|c|c|c|c|c|c|c|c|c|c|c|}
\hline & $\begin{array}{l}\text { Serra } \\
\text { verde }\end{array}$ & $\begin{array}{c}\text { Cruzeiro } \\
\text { de Cerro } \\
\text { Corá }\end{array}$ & $\begin{array}{c}\text { Vale } \\
\text { Vulcâ- } \\
\text { nico }\end{array}$ & $\begin{array}{c}\text { Mirante } \\
\text { Santa } \\
\text { Rita }\end{array}$ & $\begin{array}{l}\text { Pico do } \\
\text { Totoró }\end{array}$ & $\begin{array}{c}\text { Morro } \\
\text { do Cru- } \\
\text { zeiro }\end{array}$ & $\begin{array}{l}\text { Mina } \\
\text { Brejuí }\end{array}$ & $\begin{array}{l}\text { Cânion } \\
\text { dos } \\
\text { aper- } \\
\text { tados }\end{array}$ & $\begin{array}{l}\text { Açude } \\
\text { Garga- } \\
\text { lheiras }\end{array}$ & $\begin{array}{c}\text { Cru- } \\
\text { zeiro } \\
\text { de } \\
\text { Acari }\end{array}$ & $\begin{array}{c}\text { Poço } \\
\text { de } \\
\text { Arroz }\end{array}$ & $\begin{array}{c}\text { Marmita } \\
\text { do Rio } \\
\text { Car- } \\
\text { naúba }\end{array}$ & $\begin{array}{c}\text { Monte } \\
\text { do } \\
\text { Galo }\end{array}$ & $\begin{array}{l}\text { Xique- } \\
\text { Xique }\end{array}$ & $\begin{array}{l}\text { Açude } \\
\text { Boquei- } \\
\text { rão }\end{array}$ & $\begin{array}{c}\text { Mira- } \\
\text { dor }\end{array}$ & $\begin{array}{l}\text { Mé- } \\
\text { dia }\end{array}$ \\
\hline $\begin{array}{c}\text { Valor de Uso } \\
\text { Científico } \\
\text { (VUC) }=(2 \times V i \\
+3 \times V \text { ci }) / 5\end{array}$ & 3,30 & 1,65 & 3,10 & 1,50 & 3,75 & 1,95 & 3,55 & 2,95 & 2,95 & 2,60 & 1,55 & 2,40 & 1,45 & 3,00 & 3,10 & 2,60 & 2,38 \\
\hline $\begin{array}{l}\text { Valor de uso } \\
\text { turístico (VUT) } \\
=(3 \times V \text { tur }+ \\
2 \times V u g) / 5\end{array}$ & 1,70 & 2,23 & 1,64 & 1,11 & 2,70 & 2,27 & 3,49 & 2,35 & 2,66 & 2,05 & 1,45 & 1,45 & 3,12 & 3,13 & 2,65 & 1,63 & 2,01 \\
\hline $\begin{array}{c}\text { Valor de } \\
\text { Conservação } \\
(\mathrm{VC})=(3 \mathrm{xVi}+ \\
\mathrm{Vci}+\mathrm{Vug}) / 5\end{array}$ & 3,28 & 2,41 & 2,95 & 2,16 & 3,57 & 2,71 & 3,59 & 3,01 & 2,87 & 2,64 & 2,29 & 2,69 & 2,60 & 2,89 & 3,04 & 2,61 & 2,69 \\
\hline $\begin{array}{c}\text { Relevância } \\
(\mathrm{R})= \\
\{2 \mathrm{x}[(\mathrm{VUC} / 20) \\
\mathrm{x} 100]+ \\
{[(\mathrm{VUT} / 20)} \\
\text { x100] } / 3\end{array}$ & 13,83 & 9,22 & 13,07 & 6,86 & 17,00 & 10,29 & 17,64 & 13,75 & 14,27 & 12,09 & 7,59 & 10,42 & 10,03 & 15,22 & 14,75 & 11,39 & 11,28 \\
\hline $\begin{array}{c}\text { Tipo de } \\
\text { Relevância: } \\
\text { L (Local); R } \\
\text { (Regional); N } \\
\text { (Nacional); I } \\
\text { (Internacional) }\end{array}$ & $\mathrm{N}$ & $\mathrm{L}$ & $\mathrm{N}$ & $\mathrm{L}$ & I & $\mathrm{R}$ & I & $\mathrm{N}$ & $\mathrm{N}$ & $\mathrm{N}$ & $\mathrm{L}$ & $\mathrm{R}$ & $\mathrm{R}$ & $\mathrm{N}$ & $\mathrm{N}$ & $\mathrm{N}$ & \\
\hline
\end{tabular}

Fonte: Pesquisa de Campo (2013) 